\title{
A hybrid approach of VIKOR and bi-objective integer linear programming for electrification planning in a disaster relief camp
}

\author{
Hanif Malekpoor $^{1} \cdot$ Konstantinos Chalvatzis $^{1,2}$. \\ Nishikant Mishra ${ }^{3}$. Amar Ramudhin ${ }^{4}$
}

Published online: 11 May 2018

(C) The Author(s) 2018

\begin{abstract}
In this paper, we provide a model which optimizes the allocation of electricity generation systems, in terms of their number and location, in a disaster relief camp. The objectives that this model takes into account are minimization of the total cost of the project and prioritization of those generation systems that perform favourably. Energy and specifically electricity plays an important role in the provision of essential needs like lighting, water purification, heating, ventilation and medical care for displaced people. Disaster relief camps are commonly considered as off-grid projects, so individual generation and control systems are the main means of electrification. To support decision makers in electrification planning for temporary and semi-temporary camps, we propose a bi-objective integer linear programming model. The performance evaluation of technologies such as fuel generators, wind turbines and solar panels is conducted with an MCDM (VIKOR) approach. The model is applied on a hypothetical but realistic map site with data regarding commercially available equipment. The better performance of solar panels regarding the evaluation criteria have made them the dominant applied source of renewable electricity generation system and together with application of micro-grids in the model they have proven to reduce the cost of generation significantly. However, installing fuel generators have been found necessary for facilities which can cause a remarkable damage in case of electricity interruption. The model is promising in helping relief aid agencies to design an electrification project with minimum cost and maximum utility.
\end{abstract}

Keywords Disaster relief · VIKOR · Bi-objective integer programming · Off-grid · Electrification

\footnotetext{
Nishikant Mishra

mishra09@gmail.com

1 Norwich Business School, University of East Anglia, Norwich, UK

2 Tyndall Centre for Climate Change Research, University of East Anglia, Norwich, UK

3 Hull University Business School, University of Hull, Hull, UK

4 The Logistics Institute, University of Hull, Hull, UK
} 


\section{Introduction}

Conflict and disasters are the main causes of forcible people displacement. Conflict refers to man-made armed engagement and disasters refer to natural catastrophes ranging from floods to drought and earthquakes. The common thread between them is that they damage the infrastructure that supports people's livelihood by the destruction of house-stock or the interruption of necessary provisions such as those of clean water; energy; sanitation; and food.

By the end of 2016, a record number of 65.3 million people are forcibly displaced from their homes, and 34.000 more people are added to this list daily. 21.3 million of these people are recognised refugees and approximately half of those with refugee status are coming from only three countries; Syria $4.9 \mathrm{~m}$; Afghanistan $2.7 \mathrm{~m}$; and Somalia $1.1 \mathrm{~m}$. Temporality is a significant parameter as it defines the time length of the displacement as well as the appropriate responses regarding humanitarian aid action (UNHCR (United Nations High Commissioner for Refugees) 2017). While the leading causes of people displacement are identified as military conflicts and natural disasters it is important to acknowledge the role of climate change in exacerbating and intensifying the problem and affecting the length of their displacement (Arnall and Kothari 2015). It is estimated that, since 2008, 22.5 million people are displaced annually because of climate and weather-related disasters, and this particular segment of displaced people is growing faster than any other category (IDMC (Internal Displacement Monitoring Centre) 2015).

Such events draw the attention of media and the public worldwide and grow awareness of organizations and governments to develop methods and solutions to prevent the casualties or damages firstly, and secondly, perform relief operations with maximum efficiency. In the immediate aftermath relief operation, response time in rescuing and providing aid to injured victims is number one priority (Safar 1986). However, following the first shock, victims need to be accommodated in camps as refugees, which is when complex decisions must be taken in order to coordinate action and transform this acute issue into a multi criteria problem.

While most displaced people are being hosted in areas nearby their original homes sometimes, when they flee major disasters, they find shelters further away. The main refugeehosting countries are in the MENA region (39\%), Africa (29\%) and Asia and Pacific (14\%). Only $6 \%$ of refugees are hosted in Europe and $12 \%$ in the Americas. Hosting conditions in most cases consist of temporary, semi-permanent and long-term settlements of light container type buildings and tents. As well as logistics and medical equipment, rudimentary infrastructure facilities and means of energy supply are among substantial problems to consider. Un-interrupted access to electricity is a determining factor as it can support all the other activities and urgent or essential operations (Malekpoor et al. 2017) at a number of different scales (Pappas and Chalvatzis 2017; Pappas et al. 2017). Providing an optimal solution to electricity generation problem in a disaster relief camp regarding the position and distribution of the generation systems is extremely necessary for both residents and camp officials.

The areas available for hosting displaced people are often poorly connected to electricity, water, gas and communications utilities and even road transport may be limited. Even in major disasters i.e. floods and earthquakes, which happen in well-connected areas the disaster event can damage access to utilities and transport services. However, lifesaving equipment, hospitals and sanitation facilities need reliable, consistent power supply. This is by no means a niche domain of marginal interest. It is estimated that the energy costs for displaced people exceed \$2bn annually and this cost is growing every year due to the larger number of people in need (Chatham House 2015). At the same time, the way energy is provided in temporary 
and semi-temporary settlements leads to energy shortage with knock-on effects on clear water supply; food storage; safety; basic thermal comfort; and communications. The results of inadequate energy supply are felt in all life aspects of the most vulnerable people (Lehne et al. 2016).

Therefore, off-grid energy provision can be instrumental in making these camps suitable for hosting people. Off-grid power refers to the generation that is not connected to a robust transmission network and can include microgrids which distribute electricity a set of consumers or stand-alone generators supplying a single consumer. Energy supply in isolated systems is generally considered as the most vulnerable in terms of supply security (Chalvatzis and Ioannidis 2017a; Ioannidis and Chalvatzis 2017). Thus, the main objective of this paper is to present an optimization model of an off-grid electricity system which provides the optimal types and capacity of generation systems and their location within the camp; by taking into account the cost of generation as well as utility of the generation systems to meet the multiple required expectations and needs of the camp residents. Furthermore, the system needs to be modular to respond to a range of different size camps.

The needs that must be met vary depending on the size of camps, their expected service duration and the time in which they should be installed. However, they generally include residencies with heating and cooling; indoors and outdoors lights; capacity to charge basic ICT equipment which even though requires low power is very important to users (Pothitou et al. 2016, 2017). Moreover, camps may have basic cooking and food storage facilities as well as medical units of varying capacity.

Several different technologies can be generally used for off-grid electrification and specifically for the electrification of disaster relief camps. These include various types of fuel generators; renewable energy technologies such as wind turbines and solar panels. These types of generators can be used independently or in combined hybrid systems and they can also be paired with energy storage systems. Their main characteristics are described below.

\subsection{Fuel generator}

Fuel generators are being used for power supply in numerous occasions. Fuel generators are used in various emergency relief scenarios, grid connected backup systems and to off-grid base-load generation. It is almost impossible to compete with fuel generators on a levelised cost of electricity basis (Salehin et al. 2011). While the mass production leads to lower Fuel generator cost, there are substantial drawbacks in their use for emergency relief camps. Their main vulnerability is the fact that they require fuel to run. Disaster zones, whether natural or man-made are usually hard to access due to damages to the logistics infrastructure, hazardous routes or being in a remote geographical location. Thus, the logistics operation of continuously carrying enough fuel to these locations can be a significant challenge. Additionally, burning fossil fuels causes high level of greenhouse gas emissions (Kaldellis et al. 2004) and other air pollutants (Spyropoulos et al. 2005; Kaldellis et al. 2006; Kaldellis and Chalvatzis 2005). Also, this type of generators commonly produces loud noise and can be disturbing during continuous operation.

\subsection{Wind turbine}

Wind energy is one of the most environmentally friendly energy sources available today. With no need for any type of fuel wind turbines have a considerable advantage over fuel generators. However, wind intermittency and wind speed variability make the use of wind turbines a challenge, especially in a fragile grid system. Energy storage and the combination 
of wind turbines with other generators in hybrid systems can be an appropriate solution (Zafirakis et al. 2015). At the same time, it might be difficult to co-locate wind turbines and a disaster relief camp because of inherently different objectives. Ideally, a camp with temporary constructions and even tents should be in a sheltered area whereas a wind turbine should be exposed to wind.

\subsection{Photovoltaic system}

PV cells benefit from a very low maintenance cost as there are no moving parts. Also, due to their geometry and size, their logistics and warehouse operations offer flexible deployment when compared to other types of generators. Moreover, operating without creating any noise and pollution gives them a unique advantage. However, they are only functional on daylight and so they should be functioning alongside a storage system to provide a consistent electricity supply (Zafirakis et al. 2014). High capital cost relative to other generators can be a disadvantage for PV cells even though their costs have dropped dramatically over the past decade (Mundada et al. 2016).

\subsection{Hybrid energy systems}

Renewable energy sources are sufficient to cover the whole existing and growing energy demand. However, due to the stochastic nature of these resources, their electricity production can be intermittent or variable. This variability does not coincide for all renewable energy sources. Therefore, a renewable energy hybrid system offers a better option than a single source system in terms of cost, reliability and efficiency (Sinha and Chandel 2015). Integrating multiple systems, using different sources of energy to power electricity demand is called hybrid energy system (HES). HES can be a combination of renewable energy as well as fossil fuel generators (or any other conventional systems) with or without the use of energy storage which can be stationary with large batteries or mobile with electric vehicles (Hofmann et al. 2016). Integration of several systems together can be beneficial in the way that each system compensates drawbacks of other systems (Zafirakis and Chalvatzis 2014). However, utilizing HES efficiently and developing a stable and feasible configuration, requires the optimization of their combined systems; a task that involves many complexities due to economic, technical and environmental parameters.

This manuscript is structured as follows: following this brief introduction, a literature review on the problem and methodologies is provided in Sect. 2. Section 3 explains the methodologies that were used. After that, in Sect. 4 the model is being introduced and configuration of an individual off-grid electricity generation system is explained. Section 5 demonstrates the efficiency of the model in a case study and the results are further discussed in Sect. 6. Finally, in Sect. 7, we provide the concluding remarks and future research suggestions.

\section{Literature review}

Humanitarian relief is a reactionary provision of critical supplies of immediate needs for victims through the process of mitigating through disasters (Darcy and Hofmann 2003). This includes aid for serious and unexpected natural or man-made disasters as well as reconstruction and rehabilitation to maintain or improve quality of life of the victims during and in the aftermath of disasters or emergencies (Smith and Petley 2008, p. 73). Humanitarian logistics and supply chain are the recent focus of growing scientific and managerial literature related to 
Disaster Relief Operations (DRO). This can include logistics network restoration (HolguínVeras et al. 2012; Ransikarbum and Mason 2014, 2016; Ahmadi et al. 2015) and logistics planning and supply chain design (Mete and Zabinsky 2010; Jin et al. 2015; Kaur and Singh 2016; Charles et al. 2016; Vanajakumari et al. 2016; Fahimnia et al. 2017). Furthermore, facility location which relates directly to logistics system designs and is defined as a key decision area in disaster relief operation has been considered by different researchers (Yushimito et al. 2012; Rennemo et al. 2014; Duhamel et al. 2016; Roh et al. 2015; Paul and MacDonald 2016). In addition to Logistics and Supply Chain, provision of medicine and medical care, during and after the occurrence of a disaster has been considered by many researchers. As a significant and sensitive area, there has been a considerable number of papers in medical resource allocation (Xiang and Zhuang 2016; Sung and Lee 2016; Mohamadi and Yaghoubi 2017) and Scheduling of medical services (Rauner et al. 2012; Lei et al. 2015).

A significant body of literature focuses on operations necessary for relief activities during the immediate post-disaster operations. However, we should take into account the importance of continuous electricity supply essential to implement a great number of aforementioned operations and this supply have to be established promptly. Moreover, through disasters, people lose their home, workplace, infrastructure facilities, essentials to satisfying their basic human needs, and are dependent on governments, agencies and related organizations. This dependency can be a short-term or long-term situation. As an example, in 1992 South Florida, the hurricane Andrew destroyed around 47,000 homes. Approximately 3500 victims were housed in FEMA trailers established in 12 parks as temporary shelter until they got their permanent homes. Many of them lived in those trailers for more than 2 years and reported various social as well as health-related troubles (Edward Rappaport 1993). To these displaced people provision of electricity is necessary to provide security, healthcare, lighting and even education. The absence of electricity or delay in setting of the electricity provision equipment can significantly damage the human activities and makes the displaced people vulnerable to a wide range of distress. At the opposite end, electricity provision has a great potential to improve resilience for isolated communities (Hills et al. 2018).

Most often energy supply is organised at a national or regional level and historically security of supply has been guaranteed around the concept of state control over power generation (Chalvatzis and Rubel 2015; Chalvatzis 2009). However, these concepts do not fit the needs of off-grid generation which can be better fitting in the diversity paradigm of energy security (Chalvatzis and Ioannidis 2017b). Mandelli et al. (2016) compared the off-grid and small scale electricity production system with other available options for rural and remote areas and concluded the most appropriate option for providing electricity to isolated areas, with often poor infrastructures and services, is off-grid electrification. The role of small scalegenerators in off-grid electrification and specifically renewable generators, is increasing due to the unique advantage they offer. Decreasing the cost of transmission, reliable energy production, increased security and decreased vulnerability during accidents and environmental and social concerns can be counted for the increasing trend of small-scale generator popularity (Pepermans et al. 2005; Gulli 2006; Karger and Hennings 2009; Rae and Bradley 2012). An important problem to be dealt with in this area is that of configuration, allocation and optimal sizing of the generators. In other words, which generators of different types with how much capacity should be installed in which location of the area under development. This problem should be solved in a way that allows the development of a stand-alone system based on renewable energy sources at the lowest economic and environmental cost (Siddaiah and Saini 2016).

As previously explained, allocation and optimal sizing of generators, in a disaster relief camp, is a subset of stand-alone and off-grid electricity optimization problem. A significant 
body of literature in this domain is related to finding the best choice of electricity sources and optimizing the size and the mixed share of the sources for a specific load (Zafirakis et al. 2016). Abedi et al. (2012) developed a model which considered a system with several widely-used generators in off-grid systems, including wind turbines, PV panels, fuel cells, electrolysers, hydrogen tanks, batteries, and diesel generators. By applying differential evolutionary algorithm they solved a mixed-integer nonlinear multi-objective optimization problem with optimum monthly tilt angles of PV panels, optimum tower height for wind turbines and optimum sizing of each of the model components. Kolhe et al. (2015) investigated the optimal sizing and components for an off-grid electrification project in a remote village in Sri Lanka. All the calculations and sensitivity analysis were performed with HOMER software. A combination of PV-solar cells, wind turbines and a few diesel generators were selected as the optimal configuration. HOMER has been widely used in simulation of off-grid system sizing (Peerapong and Limmeechokchai 2017; Shahzad et al. 2017; Chaichan et al. 2016; Singh et al. 2015; Sen and Bhattacharyya 2014; Ghasemi et al. 2013).

Hocaoğlu et al. (2009), applied loss of load probability methods (LLP) in the Eskisehir region in Turkey, to obtain optimum battery capacity, together with the optimum number of PV modules and wind turbines subject to minimum cost. Merei et al. (2013), developed a model which optimized the size of wind turbines and PV generators and selected the appropriate type of battery for Aachen region in Germany by minimizing the operation cost and considering the demand satisfaction of the region. Then, they re-run the model for a region in Syria to compare the results for two regions with different weather input data. Maleki et al. (2016), analysed optimal sizing of a hybrid system of photovoltaic, wind and battery based on the cost of the system by particle swarm optimization (PSO) technique and considered the uncertainty in demand, irradiation and wind speed with Monte Carlo simulation.

When it comes to allocation of facilities and modelling problems with discrete variables, Mixed Integer Programming (MIP) has proven to be a very efficient technique (Veerapen et al. 2015). MIP has been applied in a wide range of domains and successfully facilitated the process of decision making and discrete optimization, including logistics and supply chain (Diabat and Al-Salem 2015; Demirel et al. 2016); health-care scheduling (Kim and Mehrotra 2015; Bagheri et al. 2016); and transportation (Wang et al. 2013; Omer and Farges 2013). MIP has been applied in energy and in particular electricity planning widely. Medina et al. (2013), presented a mixed-integer linear programming approach to find out the optimal type, size and allocation of distributed generators in a radial distribution system. However, they developed the model based on one objective function and only considered the minimization of the cost. Ferrer-Martí et al. (2013), developed a model for allocation of PV panels and wind generators in a remote area in Peru. They solved the model by both integer linear programming and binary linear programming and compared the results in terms of final solution and running time of the models. Moreover, for the first time, they considered the application of micro grids and isolated systems as well as each other for off-grid electrification. Their approach used single objective model and only considered the fixed cost of equipment installation.

There has only been limited research investigating the electrification of a disaster relief camp and mostly their focus is on the technologies that can be used for resilience or technical equipment and the engineering issues related to them (Uchida et al. 2012; Abbey et al. 2014; Janko et al. 2016). Salehin et al. (2011) obtained the share of electricity generation among various generator types for an emergency energy module to be used in post-crisis disaster relief camps. The optimization and simulation process was performed by HOMER and for sensitivity analysis, they included two locations with different wind speed and solar irradiation profile. The objective of their work was to meet the demand for the minimum cost. 
To the best of our knowledge, there has been no research proposing a model for designing an isolated off-grid electrification system for a disaster relief camp. Therefore, the unique characteristics, essential to the task, such as the integration of individual systems and micro grids are not adequately explored in conjunction.

\section{Hybrid approach of BOILP and VIKOR for off-grid energy supply}

In this section, the overall proposed solution to electricity generation equipment allocation in a disaster relief camp is explained and the methodologies applied in this manuscript are reviewed. In this paper, we put forward a bi-objective integer linear programming (BOILP) to allocate available generators to consumption points, while minimizing the total cost of system components and maximizing the utility value of available generators. We obtain the utility value of each generator, with MCDM evaluation between the most common generator types (solar PV, wind and fuel) used in emergency relief camps. The MCDM evaluation is performed by VIKOR technique to give an advantage to the generator which has the closest performance to the ideal performance. At the same time, it considers and eliminates potential very low performance of an alternative against a certain criterion. The MCDM evaluation results were used as the utility score in the BOILP model and allowed the reduction of the number of objective functions and the inclusion of non-quantifiable criteria into our problem. Moreover, by reducing the number of objective functions computation time was reduced significantly and it improved the model and precision of the results. Figure 1 shows the proposed solution procedure for disaster relief camp electrification design.

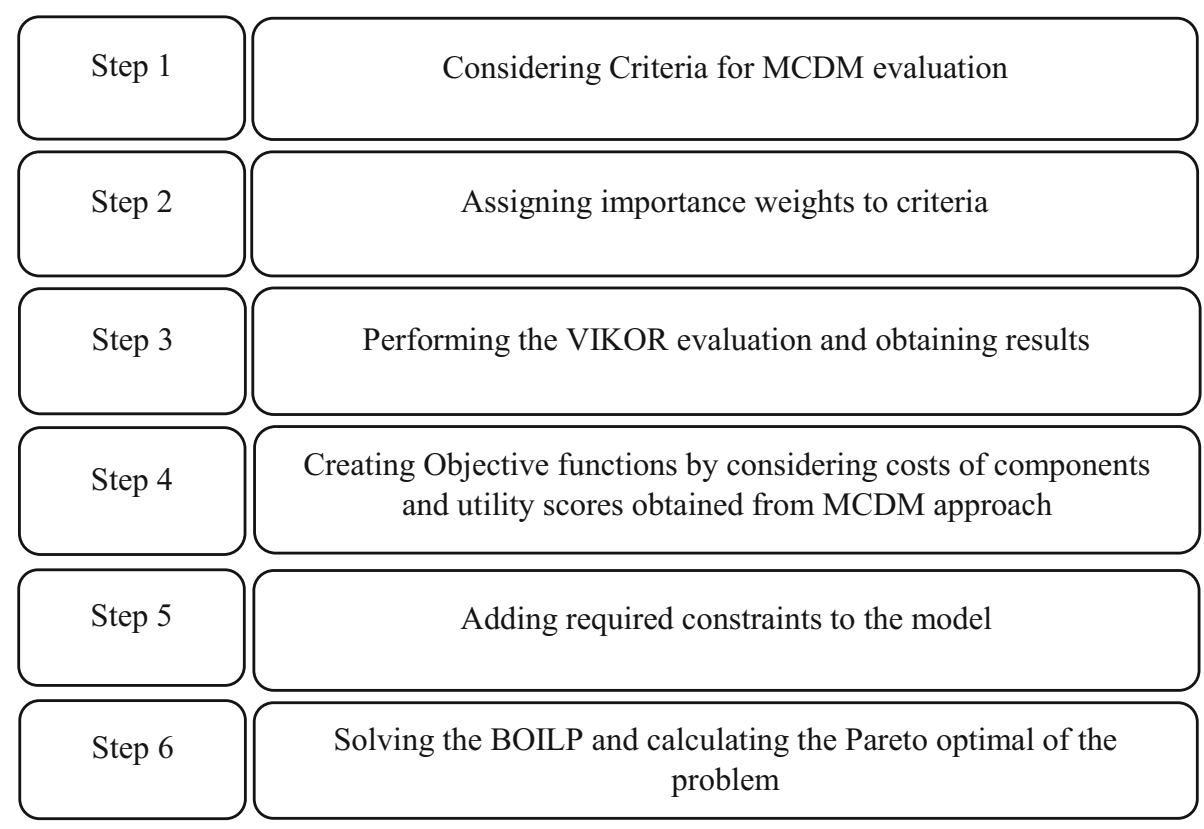

Fig. 1 The integrated VIKOR-BOILP approach 


\subsection{Methodology}

To evaluate the alternatives options in our problem (single generator types), we applied VIKOR, a MCDM technique, which presents several advantages. VIKOR considers a high ranking for the nearest alternative to our hypothetical ideal solution, while it also tries to avoid the alternative which has an exceptionally weak performance in respect to one of the criteria despite satisfactory performance in all other criteria. The latter can be very important in electrifying remote or difficult to access areas as preventing potential liabilities is an important feature of disaster relief camps. Thereafter, our final result is obtained through solving an optimization problem of multi objective integer linear programming.

\subsubsection{VIKOR}

VIKOR method is a MCDM technique which introduces the multi-criteria ranking index based on the particular measure of "closeness" to the "ideal" solution (Opricovic 1998). VIKOR is developed to rank alternatives in the presence of conflicting criteria through compromise programming of MCDM. Consider various alternatives as $\left\{A_{1}, A_{2}, \ldots, A_{j}\right\}$ and $\mathrm{j}$ is the number of those alternatives. $f_{i j}$ is the value of alternative $\mathrm{j}$ for the $i$ th criterion, and $D M=\left[f_{i j}\right]$ is the decision matrix. The compromise ranking method could be reviewed as follows:

(a) Determine the best solution as $f_{i}^{*}$ and the worst solution as $f_{i}^{-}$so that:

$$
\left\{\begin{array}{l}
f_{i}^{*}=\max _{j} f_{i j}, \quad f_{i}^{-}=\min _{j} f_{i j} \text { if criterion }(i) \text { belongs to benefit function } \\
f_{i}^{*}=\min _{j} f_{i j}, \quad f_{i}^{-}=\max _{j} f_{i j} \text { if criterion }(i) \text { belongs tocost function }
\end{array}\right.
$$

(b) Compute the values of $S_{j}$ and $R_{j}$ for $j=1,2, \ldots, n$ by Eqs. 2 and 3:

$$
\begin{aligned}
S_{j} & =\sum_{j=1}^{n} w_{i}\left(f_{i}^{*}-f_{i}\right) /\left(f_{i}^{*}-f_{i}^{-}\right) \\
R_{j} & =\max _{j}\left[w_{i}\left(f_{i}^{*}-f_{i}\right) /\left(f_{i}^{*}-f_{i}^{-}\right)\right]
\end{aligned}
$$

(c) Compute the values $Q_{i}$ for $i=1,2, \ldots, m$ by Eq. 4 :

$$
Q_{i}=v\left[\frac{S_{i}-S^{*}}{S^{-}-S^{*}}\right]+(1-v)\left[\frac{R_{i}-R^{*}}{R^{-}-R^{*}}\right]
$$

In Eq. $4, S^{*}=\min _{j} S_{j}, S^{-}=\max _{j} S_{j}$ and $R^{*}=\min _{j} R_{j}, R^{-}=\max _{j} R_{j}$;

Also, $v$ is introduced as a weight for strategy of maximum group utility, the resolving coefficient, therefore $(1-v)$ is the weight for individual regret. While $(v>0.5)$ the ranking will be representing the majority role and if $(v<0.5)$ the effect of the worst individual opponent will be highlighted more in the ranking.

(d) Rank alternatives based on values $Q_{i}$. The smaller the $Q$ is in value, the better rank alternative $i$ has among other options.

(e) In addition to having the min $\mathrm{Q}_{i}$, propose alternative $\mathrm{A} 1$ as compromised solution if the following conditions are satisfied:

C1: This condition is named "acceptable advantages":

$$
Q\left(A_{m}\right)-Q\left(A_{2}\right) \geq D Q,
$$


where $\mathrm{A} 2$ is the second best alternative and $D Q=1 /(j-1), j$ is number of alternatives.

C2: This condition is named "acceptable stability in decision making":

Alternative A1, which is best in the overall ranking, should also be best when ranked by S or R.

Therefore, if condition 2 is not satisfied alternatives A1 and A2 would be selected as compromised solution and if condition 1 is not satisfied alternatives A1 till $A_{m}$ would be selected for minimum m thus: $Q\left(A_{m}\right)-Q\left(A_{2}\right) \geq D Q$.

\subsubsection{Bi-objective integer linear programming (BOILP)}

Multi-Objective Integer and Mixed Integer Linear programming (MOILP/MOMILP) is effective in numerous cases with models which incorporate discrete events or optimizing facilities which require separated equipment. However, only a limited number of models for solving MOILP, compared to multi-objective linear programming (MOLP), with continuous variables, have been developed and applied (Alves and Clímaco 2007). Introducing integer variables to an optimization problem makes it much more complex. Bi-objective integer programming (BOIP) is a particular type of MOIPs in which the number of objectives is two. The BOIP problem can be defined as:

$$
\begin{array}{ll}
\text { Min } & f_{1}(x) ; \\
\text { Min } & f_{2}(x) ; \\
\text { s.t. } & A x \geq B \\
& x \in X,
\end{array}
$$

where $X$ is a set of feasible values for variables in which all $x_{j}$ for all $\{j=1,2, \ldots, n\}$ is a positive integer. $A$ is a set of coefficients for variables in the constraints and $B$ is a set of lower bounds for the required constraints.

The most widely used method for solving BOIP is the weighted $\varepsilon$-constraint method, which can be programmed as a single objective Integer Programming problem. Because of availability of efficient software for solving single objective Integer Programming problems, it can be applied to large problems with large number of variables. In Pareto bi-objective integer optimization the optimal result corresponds to a set of non-dominated solutions. Through applying weighted $\varepsilon$-constraint method a set of non-dominated optimal solutions can be obtained. The concept of efficiency or non-dominance in multi-objective (mixed) integer programming is defined as usually for multi-objective mathematical programming (Alves and Clímaco 2007). For a minimization objective function:

A solution $x^{\prime} \in X$ is efficient non-dominated if and only if there is no $x \in X$ that makes $f_{i}(x) \leq f_{i}\left(x^{\prime}\right)$ and $f_{i}(x)<f_{i}\left(x^{\prime}\right)$ for at least one $i$.

A solution $x^{\prime} \in X$ is not efficient if and only if there is no $x \in X$ that makes $f_{i}(x)<f_{i}\left(x^{\prime}\right)$ for all $i=1$ and 2 .

In order to obtain the non-dominated optimal Pareto set of a BOIP, in weighted $\varepsilon$-constraint method we introduce an additional constraint to the single objective weighted sum of all objectives. This constraint imposes an upper bound on one of the objectives.

$$
\begin{array}{ll}
\text { Min } & f_{1}(x)+w f_{2}(x), \\
\text { s.t. } & f_{2}(x) \leq U_{2}, \quad \text { Model (2) } \\
& A x \geq B, \\
& x \in X,
\end{array}
$$


$U_{2}$ is the upper bound of $f_{2}(x)$ and the weighted $\varepsilon$-constraint method starts to create nondominated solutions by setting $U_{2}$ as the maximum available value for $f_{2}(x)$ and then by reducing $U_{2}$ to lower bound of $f_{2}(x)$, to generate the non-dominated Pareto. The solution of the weighted $\varepsilon$-constraint method problem with $w=\frac{1}{U_{2}-L_{2}+1}$ provides an upper bound on $f_{2}(x)$ values of all bi-objective efficient solutions for a specified $U_{2}$ value (Özlen and Azizoğlu 2009). Therefore, the aforementioned problem can be transferred to the following model:

$$
\begin{array}{ll}
\text { Min } & f_{1}(x)+\left(\frac{1}{U_{2}-L_{2}+1}\right) f_{2}(x), \\
\text { s.t. } & f_{2}(x) \leq U_{2}, \\
& A x \geq B, \\
& x \in X,
\end{array}
$$

The stepwise procedure of weighted $\varepsilon$-constraint method can be described as follows:

Step 1 Obtain lower and upper bound of $f_{2}(x), L_{2}$ and $U_{2}$.

Step 2 Set $U_{2}$ as obtained upper bound of $f_{2}(x)$ in step 1 and $w$ as $\frac{1}{U_{2}-L_{2}+1}$.

Step 3 Solve model 3. Stop if the problem is infeasible.

Step 4 Store the optimal solution $x^{*}$ as one of the non-dominated solutions.

Step 5 let $U_{2}=f_{2}\left(x^{*}\right)-1$.

Go to step 3 .

The first optimal solution obtained by the aforementioned procedure returns the lower bound of $f_{1}(x)$, called $L_{1}$, and upper bound of $f_{2}(x)$, called $U_{2}$. The last solution obtained returns the upper bound of $f_{1}(x)$, called $U_{1}$, and lower bound of $f_{2}(x)$, called $L_{2}$. Each iteration of the above procedure returns an efficient non-dominated solution.

\section{Problem design}

As previously explained our proposed electrification scheme is based on a hybrid model where an individual generation system or a combination of generation systems can be allocated to a certain consumption point. Moreover, each consumption point can be supplied independently or by connecting several consumption points to form a micro-grid and supply them collectively. For each consumption point, there is a battery with adequate capacity to reduce the risk of interruption due to the intermittent power supply. Even fuel generators need to be paired with energy storage since the products used for this case study cannot be used for more than a few hours continuously. Basic demand side management technology is provided in all consumption points to control the system's stability. However, due to the existence of this device in all our consumption points, we omitted it from our mathematical model. The mathematical programming, required considerations and assumptions for our design model are explained below.

\subsection{Mathematical model}

In this manuscript, we propose a model to optimize the design of an off-grid electrification project by using independent generators, in a hybrid or individual formation. The aim of this model is to provide electricity for a disaster relief camp by considering different types of wind turbine, solar PV and fuel generators. Decision variables and indices used in the mathematical model are: 
$L$

$$
\begin{aligned}
& D i s_{L H} \\
& D e_{L} \\
& C W_{w} \\
& C P_{p} \\
& C D_{d} \\
& C B_{b} \\
& C V_{v} \\
& C a p B_{b} \\
& X W_{w L} \\
& X P_{p L} \\
& X D_{d L} \\
& X V_{L H} \\
& X E_{W L} \\
& X E_{p L} \\
& X E_{d L}
\end{aligned}
$$$$
M N W
$$$$
M N P
$$$$
M N D
$$$$
P F_{L}
$$$$
A r_{w}
$$$$
A r_{p}
$$$$
A r_{d}
$$$$
M A A_{L}
$$$$
E W_{w}
$$$$
E P_{p}
$$$$
E D_{d}
$$$$
\eta_{w}
$$$$
\eta_{p}
$$$$
\eta_{d}
$$$$
E D e_{L}
$$

Number of consumption points including residential areas, school, water purification facility, administration, hospital, storage areas etc. The different types of generators will be allocated in these places.

Distance between two consumption points of $\mathrm{L}$ and $\mathrm{H}(H \neq L)$ Electricity demand at consumption point $\mathrm{L}$

Cost of a wind turbine, type w

Cost of a solar PV module, type $\mathrm{p}$

Cost of a fuel generator, type $\mathrm{d}$

Cost of a battery, type b

Cost of a unit length of a wire type $\mathrm{v}$

Capacity of battery, type $\mathrm{b}$ in $\mathrm{kWh}$

Number of wind turbines type w, installed at consumption point L

Number of solar PV modules type p, installed at consumption point $\mathrm{L}$

Number of fuel generator type d, installed at consumption point $\mathrm{L}$

Binary variable, determining if there is a wire connection between point $L$ and $H$ or not ( 1 and 0 respectively)

Binary variable, determining if there is a wind turbine type $w$ in point $\mathrm{L}$ or not ( 1 and 0 respectively)

Binary variable, determining if there is a solar PV type $\mathrm{p}$ in point L or not (1 and 0 respectively)

Binary variable, determining if there is a fuel generator type $d$ in point $\mathrm{L}$ or not ( 1 and 0 respectively)

Maximum number of wind turbines available at one consumption point

Maximum number of solar PV modules available at one consumption point

Maximum number of fuel generators available at one consumption point

Flow of power (electricity) from any other points to consumption point $\mathrm{L}$

Space (area) needed for wind turbine, type $\mathrm{w}$ to be installed (related to the size of the turbine)

Space (area) needed for solar PV, type p to be installed (related to the size of the cells)

Space (area) needed for fuel generator, type $\mathrm{d}$ to be installed (related to the size of the generator)

Maximum allowable area for an individual or hybrid system to be installed at consumption point $\mathrm{L}$

Maximum nominal electricity output of wind turbine type w

Maximum nominal electricity output of solar PV type $p$

Maximum nominal electricity output of fuel generator type $d$

Efficiency of wind turbine type w

Efficiency of solar PV type $p$

Efficiency of fuel generator type d

Electricity demand at consumption point $\mathrm{L}$ 
$D N_{L}$

$R H_{w}$

$R H_{p}$

$R H_{d}$

Safe

$V_{\max , b L}$

$V n_{H}$

$R_{v}$

$I F$

$U E_{L}$

$E m W_{w}$

$E m P_{p}$

$E m D_{d}$

MaxAem

$S C W_{w}, S C P_{p}$ and $S C D_{d}$
Number of hours at consumption point $\mathrm{L}$ that the consumption point should rely on batteries daily

Running time (hours) of the wind turbine type w

Running time (hours) of the Solar PV type $p$

Running time (hours) of the fuel generator type $d$

Safe guarantee coefficient, which is a reliability coefficient in percentage and determines a safety margin in case there is a demand surge

Maximum output battery voltage at consumption point $\mathrm{L}$

Minimum required voltage at point $\mathrm{H}(H \neq L)$

Nominal resistance of a wire, type $\mathrm{v}$

Electrical current in our grid or system

Emergency constant demand needed at consumption point $\mathrm{L}$

Amount of $\mathrm{CO}_{2}$ equivalent released by wind turbine, type $\mathrm{w}$ for generation of $1 \mathrm{kWh}$ of electricity

Amount of $\mathrm{CO}_{2}$ equivalent released by solar PV, type $\mathrm{p}$ for generation of $1 \mathrm{kWh}$ of electricity

Amount of $\mathrm{CO}_{2}$ equivalent released by fuel generator, type $\mathrm{d}$ for generation of $1 \mathrm{kWh}$ of electricity

Maximum total allowable emissions by all systems for $1 \mathrm{~h}$ of electricity generation

Coefficients related to evaluation scores for wind turbines of type $w$, solar panels of type $p$ and fuel generators of type $\mathrm{d}$ respectively.

\subsection{Objective functions}

First objective function aims to minimize the cost of primary investments in generators and required equipment. This objective function considers the generator, batteries and the wires where there is a connection between two points and a micro grid exists.

$$
\begin{aligned}
\operatorname{Min} Z_{1}: & \sum_{w=1}^{W} \sum_{L=1}^{l} C W_{w} X W_{L w}+\sum_{p=1}^{P} \sum_{L=1}^{l} C P_{p} X P_{L p}+\sum_{d=1}^{D} \sum_{L=1}^{l} C D_{d} X D_{L d}+\sum_{b=1}^{B} \sum_{L=1}^{l} C B_{b} X B_{L b} \\
& +\sum_{H=1}^{h} \sum_{L=1}^{l} C V_{v} X V_{L H} D i s_{L H}
\end{aligned}
$$

Second objective function aims to maximize the share of the highest ranked generator. The evaluation by VIKOR in the following section gives us the coefficients of this objective function design variables.

$$
\operatorname{Max} Z_{2}=\sum_{w=1}^{W} \sum_{L=1}^{l} S C W_{w} X W_{L w}+\sum_{p=1}^{P} \sum_{L=1}^{l} S C P_{p} X W_{L p}+\sum_{d=1}^{D} \sum_{L=1}^{l} S C D_{d} X W_{L d} .
$$

\subsection{Constraints}

The set of constraints explained below has been defined based on specific conditions regarding the electrification in aid relief camps. 


\subsubsection{Demand satisfaction}

The electricity demand in each consumption point should be satisfied by the generators which are being allocated to that consumption point. Equation 7 guarantee that electricity supply can meet the demand.

$$
\begin{aligned}
& P F_{L}+\sum_{w=1}^{W} E W_{w} X W_{w L} \eta_{w}+\sum_{p=1}^{P} E P_{p} X P_{L p} \eta_{p}+\sum_{d=1}^{D} E D_{d} X D_{L d} \eta_{d} \geq(1+\text { Safe }) E D e_{L} \\
& \quad \text { for } L=1,2, \ldots, l .
\end{aligned}
$$

\subsubsection{Maximum number of generators at a location}

Due to technical reasons, space restrictions and health and safety measures there is a limitation on the maximum number of same type generators and total combination of generators that can be installed at one consumption point. Equations 8-11 describe these constraints.

$$
\begin{gathered}
\sum_{w=1}^{W} X W_{L w} \leq M N W \cdot X E_{L w} \text { for } L=1,2, \ldots, l, \\
\sum_{p=1}^{P} X P_{L p} \leq M N P \cdot X E_{L p} \text { for } L=1,2, \ldots, l, \\
\sum_{d=1}^{D} X D_{L d} \leq M N D \cdot X E_{L d} \text { for } L=1,2, \ldots, l, \\
\sum_{w=1}^{W} X W_{L w} A r_{w}+\sum_{p=1}^{P} X P_{L p} A r_{p}+\sum_{d=1}^{D} X D_{L d} A r_{d} \leq M A A_{L} \text { for } L=1,2, \ldots l .
\end{gathered}
$$

\subsubsection{Voltage drop in grids}

Equations 12-14 ensure the voltage drop within the micro grid is within acceptable standards to control potential hazard and electrical damage to equipment. They also prevent double allocation of any system to a consumption point when it is already part of a different micro grid and is connected to another consumption point.

$$
\begin{gathered}
V_{\text {max }, b L}-V n_{H} \geq 2 D i s_{L H} R_{v} I F X V_{L H} \text { for } H=1,2, \ldots, h \text { and } L=1,2, \ldots, L \\
\sum_{H=1}^{h} X V_{L H}+\sum_{w=1}^{W} X E_{L w}+\sum_{p=1}^{P} X E_{L p}+\sum_{d=1}^{D} X E_{L d} \leq 1 \text { for } L=1,2, \ldots, l \\
P F_{L} \leq \sum_{H=1}^{h} X V_{L H} \times\left(\sum_{w=1}^{W} E W_{w} X W_{w H} \eta_{w}+\sum_{p=1}^{P} E P_{p} X P_{H p} \eta_{p}+\sum_{d=1}^{D} E D_{d} X D_{H d} \eta_{d}\right) \text { for } L=1,2, \ldots, l .
\end{gathered}
$$

\subsubsection{Emergency backup power}

In aid relief camps, there are vital facilities which require secure and uninterrupted power supply, to avoid damage to equipment or risks for lives of vulnerable people. Fuel generators are used to provide this backup role and compensate for the intermittent nature of renewable energy sources (Eq. 15).

$$
\sum_{d=1}^{D} E D_{d} X D_{L d} \eta_{d} \geq U E_{L} \text { for } L=1,2, \ldots, l .
$$




\subsubsection{Sustainable electricity generation with low emissions}

The environmental impact of electricity generation is also taken into consideration with the proxy of $\mathrm{CO}_{2}$ equivalent emissions which are limited to a certain allowance (Eq. 16).

$$
\sum_{w=1}^{W} \sum_{L=1}^{l} E m W_{w} X W_{L w}+\sum_{p=1}^{P} \sum_{L=1}^{l} E m P_{p} X W_{L p}+\sum_{d=1}^{D} \sum_{L=1}^{l} E m D_{d} X W_{L d} \leq \text { MaxAem. }
$$

\subsubsection{Control the noise level for residents}

Noise pollution is one more negative consequence of having power generation near residences and other facilities. Fuel generators produce the loudest noise and wind turbines can be noisy too depending on their technology and wind speed. Therefore, it is necessary that constraints are in place to prevent excessive noise near residential shelters (Eq. 17).

$$
\sum_{d=1}^{D} \sum_{r=1}^{R} X D_{r d}=0
$$

In Eq. 17, $r=1, \ldots, R$ are consumption points, assigned to the residential shelters.

\subsubsection{Battery installation}

Batteries installed in each consumption point must support the provision of adequate capacity (Eq. 18). The balance of the system is supported by basic demand side control technologies that enable load rejection in cases of inadequate supply.

$$
\begin{aligned}
& \sum_{b=1}^{B} \operatorname{Cap}_{b} X B_{L b} \geq\left(P F_{L}+\sum_{w=1}^{W} \frac{E W_{w} X W_{w L} \eta_{w}}{R H_{w}}+\sum_{p=1}^{P} \frac{E P_{p} X P_{L p} \eta_{p}}{R H_{p}}+\sum_{d=1}^{D} \frac{E D_{d} X D_{L d} \eta_{d}}{R H_{d}}\right) \times D N_{L} \\
& \quad \text { for } L=1,2, \ldots, l .
\end{aligned}
$$

\subsection{Criteria for different systems multi-criteria evaluation}

The evaluation of the different electricity generators through the second objective function was performed based on criteria relating to various aspects of their performance. A total number of seven criteria were initially sourced from an extensive literature review and further elicitation by experts' opinion. Thereafter they were used for the coefficients $S C W, S C P$ and $S C D$ (Table 1).

\section{Case study and data}

An exemplar camp map, according to the planning and configuration of a real disaster relief camp has been designed and coordinates have been assigned to the consumption points. Figure 2 shows the camp map where blue boxes are residential shelters and specifications and facilities and buildings of the camp are considered as Table 2.

The camp is designed in an area with $380 \mathrm{~m}$ width and $360 \mathrm{~m}$ in length and can accommodate up to 229 people. For a large-scale disaster zone, this camp can be considered arguably small. Indeed, several disaster zones require capacity of thousands of people and in this sense, 
Table 1 Criteria and their description for MCDM evaluation

\begin{tabular}{lll}
\hline Criterion & Description & References \\
\hline Brand reputation and credibility & $\begin{array}{c}\text { Reliability and after-sale support } \\
\text { provided by the manufacturer } \\
\text { Interruption risk due to intermittent } \\
\text { resource supply }\end{array}$ & Van de Kaa et al. (2014) \\
Emissions & $\begin{array}{l}\text { Amount of GHGs emissions for } \\
\text { electricity generation }\end{array}$ & Streimikiene et al. (2012) \\
Maintenance cost & $\begin{array}{l}\text { Costs related to maintenance and } \\
\text { keeping the equipment operational } \\
\text { and reliable }\end{array}$ & Kaya and Kahraman (2010) \\
Ease of storage for generator and & $\begin{array}{l}\text { How easily can the equipment be } \\
\text { stored in case of no usage and the } \\
\text { fuel provision }\end{array}$ & Experts \\
Land use & $\begin{array}{l}\text { Limited area in camps, human safety } \\
\text { concerns and difficulties in } \\
\text { designing the plan of the camp } \\
\text { make the systems which require } \\
\text { less area for installation and } \\
\text { operation preferable }\end{array}$ & Experts \\
& $\begin{array}{l}\text { How much noise is produced during } \\
\text { the system's operation }\end{array}$ & Kaya and Kahraman (2010) \\
Noise production & &
\end{tabular}

it might seem that our camp case study is unrealistic. However, the value of flexibility that modularity can offer should not be disregarded. Our aim in designing a relatively small camp is to facilitate an overall design strategy for numerous similar adjacent camps that can be put in place to accommodate for a large number of people and equally they can be removed when this requirement is not there anymore. Moreover, not all disaster areas are flat and suitable for large continuous camps. In mountainous or coastal cliff areas camps need to be small and modular to accommodate the peculiarities of the terrain (Fig. 2).

\subsection{Generator, turbine and panels}

The alternatives, in terms of generation equipment, are based on expert opinions and are among the most common and efficient electricity generation systems. Specific makes and models vary but the ones selected represent a range of options and are typical of what is available in the market. Clarke CP6550NESLR 6.5 and 11.25 kVA Hyundai (DG1 and DG2) are the alternatives for fuel generators with nominal output of 6.5 and $10 \mathrm{~kW}$. Sunpower E20 and Samsung LPC250SM (PV1 and PV2) are alternatives for solar PV and Bergey Excel $10 \mathrm{~kW}$ and Gaia-wind (WT1 and WT2) are the selected alternatives for wind electricity generation (Table 3).

Energy storage has been considered in the form of two Lithium-Ion batteries with capacity of 13.5 and $27 \mathrm{kWh}$ and cost of $£ 6500$ and $£ 28,560$ respectively.

The hypothetical latitude for this camp has been assumed between $40^{\circ}$ and $41^{\circ}$ which impacts the tilt of solar PVs (assumed to be installed in fixed configuration) and the area they occupy. The average wind speed has been assumed based on wind trajectories near Istanbul city and is acknowledged that it can be significantly different depending on the specific location. 
Table 2 Facilities and buildings considered for the camp

\begin{tabular}{|c|c|}
\hline Facility & Specifications \\
\hline Administration and management office & $\begin{array}{l}\text { One office; electricity demand: } 38.5 \mathrm{kWh} \text {; emergency demand: } \\
32 \mathrm{kWh} \text { per day }\end{array}$ \\
\hline Market centre and bakery & $\begin{array}{l}\text { One facility; electricity demand: } 42.5 \mathrm{kWh} \text {; emergency demand: } \\
28 \mathrm{kWh} \text { per day }\end{array}$ \\
\hline Health centre & $\begin{array}{l}\text { One treatment facility for minor injuries and advisory aid; } \\
\text { electricity demand: } 48.5 \mathrm{kWh} \text {; emergency demand: } 35.6 \mathrm{kWh} \text { per } \\
\text { day }\end{array}$ \\
\hline Hospital & $\begin{array}{l}\text { One hospitalization facility with } 15 \text { beds; electricity demand: } \\
188.5 \mathrm{kWh} \text {; emergency demand: } 165 \mathrm{kWh} \text { per day }\end{array}$ \\
\hline Emergency Health Centre & $\begin{array}{l}\text { One facility for serious injuries; electricity demand: } 105 \mathrm{kWh} \text {; } \\
\text { emergency demand: } 100.5 \mathrm{kWh} \text { per day }\end{array}$ \\
\hline Water purification centre & $\begin{array}{l}\text { One facility for clean water provision and pumping; electricity } \\
\text { demand: } 135.5 \mathrm{kWh} \text {; emergency demand: } 75.5 \mathrm{kWh} \text { per day }\end{array}$ \\
\hline Storage facilities & $\begin{array}{l}\text { Three storage facilities including } 2 \text { refrigeration storages and } 1 \\
\text { warehouse; electricity demand: } 11.5 \text { and } 2.16 \mathrm{kWh} \text { per day } \\
\text { respectively. Fridge storages also have emergency demand: } \\
9.1 \mathrm{kWh} \text { per day }\end{array}$ \\
\hline School and learning centre & $\begin{array}{l}\text { Two classrooms with a capacity of } 40 \text { students; electricity demand: } \\
17 \mathrm{kWh} \text {; emergency demand: } 8 \mathrm{kWh} \text { per day }\end{array}$ \\
\hline Shopping centre & $\begin{array}{l}\text { One shopping facility; electricity demand: } 12 \mathrm{kWh} \text {; emergency } \\
\text { demand: } 8 \mathrm{kWh} \text { per day }\end{array}$ \\
\hline \multirow[t]{3}{*}{ Residential shelters } & $\begin{array}{l}36 \text { residential shelters with a capacity of } 4 \text { people; electricity } \\
\text { demand: } 2.8 \mathrm{kWh} \text { per day }\end{array}$ \\
\hline & $\begin{array}{l}10 \text { residential shelters with a capacity of } 5 \text { people; electricity } \\
\text { demand: } 3.2 \mathrm{kWh} \text { per day }\end{array}$ \\
\hline & $\begin{array}{l}\text { Five residential shelters with a capacity of } 7 \text { people; electricity } \\
\text { demand: } 4.5 \mathrm{kWh} \text { per day }\end{array}$ \\
\hline
\end{tabular}

The MCDM evaluation table against the criteria explained in Sect. 4.4 was based on available data and experts' opinion. Further details, including the values applied to explain the linguistic terms are available in "Appendix A".

\section{Results}

To calculate the $S W_{w}, S D_{d}$ and $S P_{p}$ coefficients which are used in the second objective function, based on VIKOR technique we evaluated the previously mentioned generation options (Table 4). The smaller the $Q_{i}$ index, the better the expected performance of the system.

As we need a coefficient that can increase the share of the generation system with better performance the score coefficients are calculated as $1-Q_{i}$.

The optimization problems have been solved by MATLAB CPLEX 12.6.1 on a computer with core i7 quad core $3.64 \mathrm{GHz}$ CPU and 32 GB RAM. According to Sect. 3.1.2 we need an upper bound for one of the objective functions and thus the objective function related to cost of the project (Eq. 5), has been chosen to be included in the constraints. For upper bound of cost objective function, to obtain acceptable and applicable results (avoiding unrealistic 


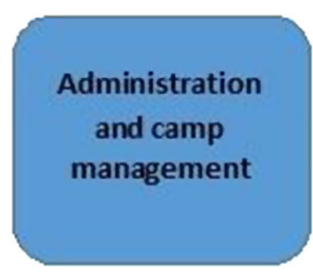

\section{Emergency} Health centre

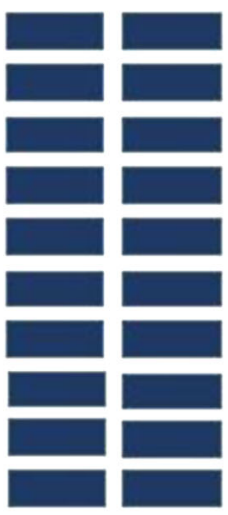

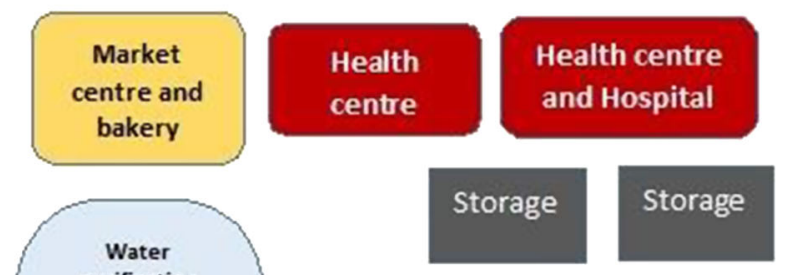

Storage
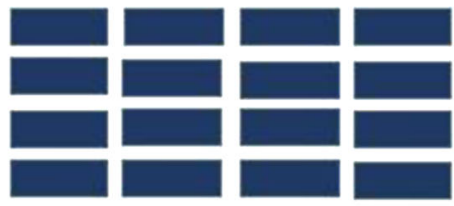

Primary and secondary school
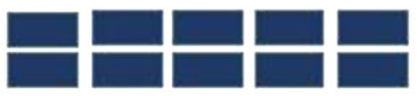

IIII

\section{Market} centre and shopping

Fig. 2 The configuration of a disaster relief camp for this study

Table 3 Cost of generation systems

\begin{tabular}{lllllll}
\hline System & DG1 & DG2 & PV1 & PV2 & WT1 & WT2 \\
\hline Cost (£) & 1618 & 3490 & 400 & 500 & 30,000 & 35,000 \\
\hline
\end{tabular}

solutions), we assumed there would be no micro grid and optimize the model and calculated the results based on that assumption. This approach significantly increases the cost of the project as can be seen in the upper bound result for cost objective function (Table 5).

By calculating the minimum amount for cost objective function, the lower bound for this objective function has been obtained based on Table 6 .

In order to obtain the non-dominated optimal Pareto, in each iteration, started with upper bound of cost function (based on steps in Sect. 3.1.2), $U_{2}$ is subtracted by 400 , which is the least expensive generation system and thereby optimal Pareto has been obtained. "Appendix 
Table 4 VIKOR result of

Table 5 Solution with no micro-grid systems' evaluation

\begin{tabular}{lllllll}
\hline System & DG1 & DG2 & PV1 & PV2 & WT1 & WT2 \\
\hline$Q_{i}$ & 0.8592 & 0.957 & 0.015 & 0.108 & 0.8308 & 0.948 \\
\hline
\end{tabular}

\begin{tabular}{ll}
\hline Type of equipment & Number of equipment \\
\hline Type 1 fuel generator & 12 generators \\
Type 2 fuel generator & One generator \\
Type 1 solar PV & 109 panels \\
Type 2 solar PV & Zero panels \\
Type 1 wind turbine & No turbine \\
Type 2 wind turbine & No turbine \\
Micro grids & No micro grids \\
\hline
\end{tabular}

Table 6 Solution with minimum cost of equipment

\begin{tabular}{ll}
\hline Type of equipment & Number of equipment \\
\hline Type 1 fuel generator & Seven generators \\
Type 2 fuel generator & One generator \\
Type 1 solar PV & Two panels \\
Type 2 solar PV & Eight panels \\
Type 1 wind turbine & No turbine \\
Type 2 wind turbine & No turbine \\
Micro grids & Seven micro grids \\
\hline
\end{tabular}

B" shows the solution for minimum cost, which is also the solution for our lower bound on the maximizing score objective function.

Wind turbines have not been possible to use in the optimal Pareto solutions. A combination of difficult and expensive installation, the high level of produced noised, the transport logistics for parts like long towers and blades, high risk of interruption and reliability on high speed winds, minimum wind turbine distance limitations as well as safety issues make them less attractive for small scale, emergency settings. On the contrary, solar PV, in particular type 2 panels with higher cost and higher electricity output compared to type 1 panels, had a high generation share in the system.

In MADM comparison both Solar PV options were evaluated significantly better than other technologies due to their low maintenance cost and noiseless operation which can make them suitable for use next to residences and other buildings. Furthermore, relief organizations have to be prepared before a disaster occurs, therefore inventory and ease of transporting the equipment to the sites is important (Zobel 2010) increasing further PV panel desirability. Considering that different solar panels perform differently our evaluation shows that the type 1 solar PV has been assigned with better score. Along the Pareto optimal, when we sacrifice the cost of equipment to obtain a solution with better evaluation scores, the share of the type 1 solar PV can increase as in Table 7, the solution with higher cost but maximised generation system scores. This solution just in the case of generation systems increases the cost by $£ 2500$. Also, the cost of used wires (considered as $£ 3.5$ per meter for this research) has an important role regarding the position of the newly installed solar PV in approaches with higher cost as well as higher utility score. The consumption points with higher distance to the 
Table 7 A solution in optimal Pareto

\begin{tabular}{ll}
\hline Type of equipment & Number of equipment \\
\hline Type 1 fuel generator & Seven generators \\
Type 2 fuel generator & One generator \\
Type 1 solar PV & 15 panels \\
Type 2 solar PV & One panels \\
Type 1 wind turbine & No turbine \\
Type 2 wind turbine & No turbine \\
Micro grids & Eight micro grids
\end{tabular}

main electricity generation system in a micro-grid were prioritized to be assigned with solar panels and this caused lower total cost for the project. This behaviour further demonstrates the robustness of the optimization model.

The decision can be adjusted based on the weights of the objective functions and the costs that can be covered by the humanitarian aid programme. For example, if the camp will only be a short-time temporary facility, then environmental quality parameters such as noise and emissions can be weighted very low or almost disregarded. Moreover, if space is not an issue then land use can be used with very low score. Furthermore, if weather conditions are mild or there are no medical facilities that require energy, power supply reliability becomes less important and in the criteria of risk of interruption and brand reputation and credibility can be used with very low weight.

Equation 15, enforces the existence of a fuel generator for facilities with emergency demand requirement and we can see throughout our Pareto-optimal solution that the electricity provided by fuel generators increases as much as the utility increases. We can relate the obligation of designing such a constraint to lack of advancement in technology of renewable systems which necessitates the application of conventional energy generation systems. Especially, when the situation or equipment requires guaranteed continuous flow of electricity like an emergency medical unit.

The use of individual distributed generators can cause as many problems as it may solve. In order to support the consumption point demands, application of micro-grids can be a clever approach (Lasseter and Paigi 2004). However due to planning restrictions in the architecture of relief camps, we put forward an approach of several micro-grids and coupling hybrid generation systems within the micro-grids in particular for consumption points that are being supplied with renewable generation systems and are in high risk of interruption. In this research, we have assumed that there could be no inner connections between micro-grids despite their benefits for cost reduction. As an example, in a situation where the electricity demand of two medical type, inelastic, loads need to be supplied through micro-grids without inner connection, the use of 2 fuel generator type 1 and a generator type 2 (Fig. 3a) is the lowest cost option available. However, with availability of inner connection between microgrids, a type 2 fuel generator could be replaced with a lower cost type 1 fuel generator, saving $£ 1872$ (Fig. 3b). Linking micro-grids can make the camp installation process more complex and increase requirements for load management equipment such as invertors and wire lines. It may as well reduce the modularity of the camp and its capacity to grow and shrink smoothly. Furthermore, it will be prone to more disruptive accidents and even life-threatening accidents as it would require a higher number of live cables crossing the camp areas. Therefore, further research would be required to look into how to incorporate internal micro-grid links and reap the potential benefits of lower costs without compromising ease of installation and flexibility. 


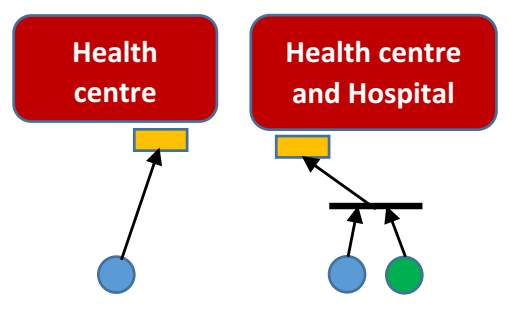

(a)

Fuel Generator type 1

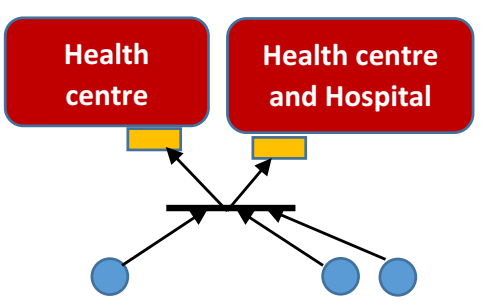

(b)

Fuel Generator type 2

Storage system

Fig. 3 Comparison in a part of our problem between inner connection allowed and not allowed condition. a Without inner connection between, $\mathbf{b}$ inner connection between

The emergency possible effect on low number of PV panels, however, possible cost effect of the increase in utility maximized solutions.

\section{Conclusion}

We present a hybrid integrated approach of VIKOR and bi-objective integer linear programming to support decision making for electrification planning within a disaster relief camp based on an individual generator configuration. Disaster relief camps, as off-grid electrification projects, require planning decisions about the type, quantity and location of the individual electricity generation systems. We have considered fuel, wind and solar systems for electricity generation and designed the optimization model based on essential factors related to disaster relief camps. Two objective functions minimize the project cost and maximize the share of systems which obtained a better performance score through VIKOR evaluation. These solutions not only consider the cost of the project but also several other significant criteria which are highly effective in developing the reliability of the system, ease of installation and providing improved livelihood for the camp residents. The proposed approach of hybrid VIKOR-BOILP can aid governmental and non-governmental organisations in charge of responding to natural and human-made disasters to promote an optimized electrification project effectively by considering the needs of both residents and the institution.

Further development of this model will include taking into account the parameters' uncertainties and increasing the total number and coverage of those parameters. This approach will enable a broader range of considerations and improved overall precision. Moreover, future research should consider the potential of creating micro-grid designs that can overcome the uncertainty in demand and supply parameters. Overcoming the inherent challenges that disaster relief camps impose such as the need for flexibility and modularity as well the very short installation times may be the key in developing designs that will be useful for commercial opportunities.

Acknowledgements The specific study has been funded under the project TILOS (Horizon 2020 Low Carbon Energy Local/small-scale storage LCE-08-2014). This project has received funding from the European Union \& Horizon 2020 research and innovation programme under Grant Agreement No. 646529. The authors would also like to thank the project 'A cross country examination of supply chain barriers on market access for small and medium firms in India and UK' (Ref No. PM130233) funded by British Academy, UK for supporting this research. 
Open Access This article is distributed under the terms of the Creative Commons Attribution 4.0 International License (http://creativecommons.org/licenses/by/4.0/), which permits unrestricted use, distribution, and reproduction in any medium, provided you give appropriate credit to the original author(s) and the source, provide a link to the Creative Commons license, and indicate if changes were made.

\section{Appendix A: Decision matrix for MCDM evaluation and values for linguistic variables}

See Tables 8 and 9 .

Table 8 Decision matrix

\begin{tabular}{|c|c|c|c|c|c|c|c|}
\hline & $\begin{array}{l}\text { Brand } \\
\text { reputation } \\
\text { and } \\
\text { credibility }\end{array}$ & $\begin{array}{l}\text { Risk of } \\
\text { interruption }\end{array}$ & $\begin{array}{l}\text { Emissions } \\
\text { (local during } \\
\text { operation) }\end{array}$ & $\begin{array}{l}\text { Maintenance } \\
\text { cost }\end{array}$ & $\begin{array}{l}\text { Ease of } \\
\text { Storage for } \\
\text { generator } \\
\text { and fuel }\end{array}$ & $\begin{array}{l}\text { Land use } \\
\left(\mathrm{m}^{2}\right)\end{array}$ & $\begin{array}{l}\text { Noise } \\
\text { Creation } \\
\text { (db) }\end{array}$ \\
\hline $\begin{array}{l}\text { Clarke CP6550NESLR } \\
6.5 \mathrm{kVA}\end{array}$ & Low & Medium & Medium & High & Low & 0.362 & 71 \\
\hline 11.25 kVA Hyundai & Low & Medium & High & High & $\begin{array}{l}\text { Medium } \\
\text { high }\end{array}$ & 0.943 & 70 \\
\hline Sunpower E20 & $\begin{array}{l}\text { Medium } \\
\text { high }\end{array}$ & Medium low & 0 & Low & $\begin{array}{l}\text { Medium } \\
\text { high }\end{array}$ & 1.357 & 0 \\
\hline Samsung & Medium & Medium & 0 & Low & Medium & 1.332 & 0 \\
\hline Bergey Excel & High & High & 0 & Medium & Low & 1.5 & 42.9 \\
\hline Gaia-wind & High & High & 0 & High & Low & 2 & 44.6 \\
\hline Weight of each criterion & 0.073 & 0.219 & 0.17 & 0.122 & 0.073 & 0.122 & 0.219 \\
\hline
\end{tabular}

Table 9 Values of linguistic terms

\begin{tabular}{ll}
\hline Linguistic term & Value \\
\hline High & 9 \\
Medium high & 7 \\
Medium & 5 \\
Medium low & 3 \\
Low & 1 \\
\hline
\end{tabular}




\section{Appendix B: Detailed numbers, type of systems and connections for minimum cost solution}

\begin{tabular}{lllllllll}
\hline $\begin{array}{l}\text { Consumption } \\
\text { point }\end{array}$ & 1 & 2 & 3 & 4 & 5 & 6 & 7 & 8 \\
\hline $\begin{array}{l}\text { Number of } \\
\text { systems }\end{array}$ & 0 & $2 \times$ DG1 & 0 & 0 & $\begin{array}{l}1 \times \text { DG1 } \\
+1 \times \text { DG } 2 \\
+2 \times \text { PV } 1\end{array}$ & $2 \times$ DG1 & $1 \times$ DG1 & 0 \\
$\begin{array}{c}\text { Connection to } \\
\text { other points }\end{array}$ & To 2 & Yes & To 6 & To 5 & Yes & Yes & Yes & To 7 \\
\hline
\end{tabular}

\begin{tabular}{lllllllll}
\hline $\begin{array}{l}\text { Consumption } \\
\text { point }\end{array}$ & 9 & 10 & 11 & 12 & 13 & 14 & 15 & 16 \\
\hline $\begin{array}{c}\text { Number of } \\
\text { systems }\end{array}$ & 0 & 0 & $1 \times$ DG1 & 0 & 0 & 0 & 0 & 0 \\
$\begin{array}{c}\text { Connection to } \\
\text { other points }\end{array}$ & To 2 & To 7 & Yes & To 2 & To 2 & To 2 & To 2 & To 2 \\
\end{tabular}

\begin{tabular}{lllllllll}
\hline $\begin{array}{l}\text { Consumption } \\
\text { point }\end{array}$ & 17 & 18 & 19 & 20 & 21 & 22 & 23 & 24 \\
\hline $\begin{array}{c}\text { Number of } \\
\text { systems }\end{array}$ & 0 & 0 & $4 \times$ PV2 & 0 & 0 & 0 & 0 & 0 \\
$\begin{array}{c}\text { Connection to } \\
\text { other points }\end{array}$ & To 2 & To 2 & Yes & To 19 & To 31 & To 2 & To 2 & To 2 \\
\hline
\end{tabular}

\begin{tabular}{lllllllll}
\hline $\begin{array}{l}\text { Consumption } \\
\text { point }\end{array}$ & 25 & 26 & 27 & 28 & 29 & 30 & 31 & 32 \\
\hline $\begin{array}{c}\text { Number of } \\
\text { systems }\end{array}$ & 0 & 0 & 0 & 0 & 0 & 0 & $4 \times$ PV2 & $3 \times$ PV2 \\
$\begin{array}{c}\text { Connection to } \\
\text { other points }\end{array}$ & To 2 & To 2 & To 2 & To 2 & To 19 & To 31 & Yes & Yes \\
\hline
\end{tabular}

\begin{tabular}{lllllllll}
\hline $\begin{array}{l}\text { Consumption } \\
\text { point }\end{array}$ & 33 & 34 & 35 & 36 & 37 & 38 & 39 & 40 \\
\hline $\begin{array}{c}\text { Number of } \\
\text { systems }\end{array}$ & 0 & 0 & 0 & 0 & 0 & 0 & 0 & 0 \\
$\begin{array}{c}\text { Connection to } \\
\text { other points }\end{array}$ & To 7 & To 7 & To 7 & To 7 & To 7 & To 7 & To 7 & To 7 \\
\end{tabular}




\begin{tabular}{lllllllll}
\hline $\begin{array}{l}\text { Consumption } \\
\text { point }\end{array}$ & 41 & 42 & 43 & 44 & 45 & 46 & 47 & 48 \\
\hline $\begin{array}{c}\text { Number of } \\
\text { systems } \\
\begin{array}{c}\text { Connection to } \\
\text { other points }\end{array}\end{array}$ & 0 & 0 & 0 & 0 & 0 & 0 & 0 & 0 \\
\hline
\end{tabular}

\begin{tabular}{lllllllll}
\hline $\begin{array}{l}\text { Consumption } \\
\text { point }\end{array}$ & 49 & 50 & 51 & 52 & 53 & 54 & 55 & 56 \\
\hline $\begin{array}{c}\text { Number of } \\
\text { systems }\end{array}$ & 0 & 0 & 0 & 0 & 0 & 0 & 0 & 0 \\
$\begin{array}{c}\text { Connection to } \\
\text { other points }\end{array}$ & To 11 & To 11 & To 11 & To 11 & To 11 & To 11 & To 11 & To 11 \\
\hline
\end{tabular}

\begin{tabular}{lllllll}
\hline $\begin{array}{l}\text { Consumption } \\
\text { point }\end{array}$ & 57 & 58 & 59 & 60 & 61 & 62 \\
\hline $\begin{array}{c}\text { Number of } \\
\text { systems } \\
\begin{array}{c}\text { Connection to } \\
\text { other points }\end{array}\end{array}$ & 0 & 0 & 0 & 0 & 0 & 0 \\
\hline
\end{tabular}

\section{References}

Abbey, C., Cornforth, D., Hatziargyriou, N., Hirose, K., Kwasinski, A., Kyriakides, E., et al. (2014). Powering through the storm: Microgrids operation for more efficient disaster recovery. IEEE Power and Energy Magazine, 12(3), 67-76.

Abedi, S., Alimardani, A., Gharehpetian, G. B., Riahy, G. H., \& Hosseinian, S. H. (2012). A comprehensive method for optimal power management and design of hybrid RES-based autonomous energy systems. Renewable and Sustainable Energy Reviews, 16(3), 1577-1587.

Ahmadi, M., Seifi, A., \& Tootooni, B. (2015). A humanitarian logistics model for disaster relief operation considering network failure and standard relief time: A case study on San Francisco district. Transportation Research Part E: Logistics and Transportation Review, 75, 145-163.

Alves, M. J., \& Clímaco, J. (2007). A review of interactive methods for multiobjective integer and mixedinteger programming. European Journal of Operational Research, 180(1), 99-115.

Arnall, A., \& Kothari, U. (2015). Challenging climate change and migration discourse: Different understandings of timescale and temporality in the Maldives. Global Environmental Change, 31, 199-206.

Bagheri, M., Devin, A. G., \& Izanloo, A. (2016). An application of stochastic programming method for nurse scheduling problem in real word hospital. Computers \& Industrial Engineering, 96, 192-200.

Chaichan, M. T., Kazem, H. A., Mahdy, A. M., \& Al-Waeely, A. A. (2016). Optimal sizing of a hybrid system of renewable energy for lighting street in Salalah-Oman using Homer software. International Journal of Scientific Engineering and Applied Science (IJSEAS), 2(5), 157-164.

Chalvatzis, K. J. (2009). Electricity generation development of Eastern Europe: A carbon technology management case study for Poland. Renewable and Sustainable Energy Reviews, 13(6), 1606-1612.

Chalvatzis, K. J., \& Ioannidis, A. (2017a). Energy supply security in Southern Europe and Ireland. Energy Procedia, 105, 2916-2922. 
Chalvatzis, K. J., \& Ioannidis, A. (2017b). Energy supply security in the EU: Benchmarking diversity and dependence of primary energy. Applied Energy, 207, 465-476.

Chalvatzis, K. J., \& Rubel, K. (2015). Electricity portfolio innovation for energy security: The case of carbon constrained China. Technological Forecasting and Social Change, 100, 267-276.

Charles, A., Lauras, M., Van Wassenhove, L. N., \& Dupont, L. (2016). Designing an efficient humanitarian supply network. Journal of Operations Management, 47, 58-70.

Chatham House. (2015). Heat, light and power for refugees saving lives, reducing costs. https:// www.chathamhouse.org/sites/files/chathamhouse/publications/research/2015-11-17-heat-light-powerrefugees-lahn-grafham-final.pdf. Accessed 3 March 2018.

Darcy, J., \& Hofmann, C. (2003). According to need? Needs assessment and decision-making in the humanitarian sector. Humanitarian Policy Group, ODI. http://agris.fao.org/agris-search/search.do?recordID= GB2013203835.

Demirel, E., Demirel, N., \& Gökçen, H. (2016). A mixed integer linear programming model to optimize reverse logistics activities of end-of-life vehicles in Turkey. Journal of Cleaner Production, 112, 2101-2113.

Diabat, A., \& Al-Salem, M. (2015). An integrated supply chain problem with environmental considerations. International Journal of Production Economics, 164, 330-338.

Duhamel, C., Santos, A. C., Brasil, D., Châtelet, E., \& Birregah, B. (2016). Connecting a population dynamic model with a multi-period location-allocation problem for post-disaster relief operations. Annals of Operations Research, 247(2), 693-713.

Edward Rappaport. (1993). Hurricane Andrew. National Hurricane Center (Preliminary Report). Miami: United States National Oceanic and Atmospheric Administration's National Weather Service. Retrieved 21 June 2012.

Fahimnia, B., Jabbarzadeh, A., Ghavamifar, A., \& Bell, M. (2017). Supply chain design for efficient and effective blood supply in disasters. International Journal of Production Economics, 183, 700-709.

Ferrer-Martí, L., Domenech, B., García-Villoria, A., \& Pastor, R. (2013). A MILP model to design hybrid wind-photovoltaic isolated rural electrification projects in developing countries. European Journal of Operational Research, 226(2), 293-300.

Ghasemi, A., Asrari, A., Zarif, M., \& Abdelwahed, S. (2013). Techno-economic analysis of stand-alone hybrid photovoltaic-diesel-battery systems for rural electrification in eastern part of Iran-A step toward sustainable rural development. Renewable and Sustainable Energy Reviews, 28, 456-462.

Gulli, F. (2006). Small distributed generation versus centralised supply: A social cost-benefit analysis in the residential and service sectors. Energy Policy, 34(7), 804-832.

Hills, J. M., Michalena, E., \& Chalvatzis, K. J. (2018). Innovative technology in the Pacific: Building resilience for vulnerable communities. Technological Forecasting and Social Change, 129, 16-26.

Hocaoğlu, F. O., Gerek, Ö. N., \& Kurban, M. (2009). A novel hybrid (wind-photovoltaic) system sizing procedure. Solar Energy, 83(11), 2019-2028.

Hofmann, J., Guan, D., Chalvatzis, K., \& Huo, H. (2016). Assessment of electrical vehicles as a successful driver for reducing $\mathrm{CO}_{2}$ emissions in China. Applied Energy, 184, 995-1003.

Holguín-Veras, J., Jaller, M., Van Wassenhove, L. N., Pérez, N., \& Wachtendorf, T. (2012). On the unique features of post-disaster humanitarian logistics. Journal of Operations Management, 30(7), 494-506.

IDMC (Internal Displacement Monitoring Centre). (2015). Global Estimates 2015: People displaced by disasters. http://www.internal-displacement.org/assets/library/Media/201507-globalEstimates-2015/ 20150713-global-estimates-2015-en-v1.pdf. Accessed 3 March 2018.

Ioannidis, A., \& Chalvatzis, K. J. (2017). Energy supply sustainability for Island Nations: A study on 8 Global Islands. Energy Procedia, 142, 3028-3034.

Janko, S., Atkinson, S., \& Johnson, N. (2016). Design and fabrication of a containerized micro-grid for disaster relief and off-grid applications. In ASME 2016 international design engineering technical conferences and computers and information in engineering conference (pp. V02AT03A056-V02AT03A056). American Society of Mechanical Engineers.

Jin, S., Jeong, S., Kim, J., \& Kim, K. (2015). A logistics model for the transport of disaster victims with various injuries and survival probabilities. Annals of Operations Research, 230(1), 17-33.

Kaldellis, J. K., \& Chalvatzis, K. J. (2005). Environment and industrial development: Sustainability and development, air pollution. Athens: Stamoulis Publications.

Kaldellis, J. K., Spyropoulos, G. C., \& Chalvatzis, K. J. (2004). The impact of Greek electricity generation sector on the national air pollution problem. Fresenius Environmental Bulletin, 13(7), 647-656.

Kaldellis, J. K., Spyropoulos, G. C., Chalvatzis, K. J., \& Paliatsos, A. G. (2006). Minimum $\mathrm{SO}_{2}$ electricity sector production using the most environmental friendly power stations in Greece. Fresenious Environmental Bulletin, 15(11), 1394-1399.

Karger, C. R., \& Hennings, W. (2009). Sustainability evaluation of decentralized electricity generation. Renewable and Sustainable Energy Reviews, 13(3), 583-593. 
Kaur, H., \& Singh, S. P. (2016). Sustainable procurement and logistics for disaster resilient supply chain. Annals of Operations Research. https://doi.org/10.1007/s10479-016-2374-2.

Kaya, T., \& Kahraman, C. (2010). Multicriteria renewable energy planning using an integrated fuzzy VIKOR \& AHP methodology: The case of Istanbul. Energy, 35(6), 2517-2527.

Kim, K., \& Mehrotra, S. (2015). A two-stage stochastic integer programming approach to integrated staffing and scheduling with application to nurse management. Operations Research, 63(6), 1431-1451.

Kolhe, M. L., Ranaweera, K. I. U., \& Gunawardana, A. S. (2015). Techno-economic sizing of off-grid hybrid renewable energy system for rural electrification in Sri Lanka. Sustainable Energy Technologies and Assessments, 11, 53-64.

Lasseter, R. H., \& Paigi, P. (2004). Microgrid: A conceptual solution. In Power electronics specialists conference, 2004. PESC 04. 2004 IEEE 35th Annual (Vol. 6, pp. 4285-4290). IEEE.

Lehne, J., Blyth, W., Lahn, G., Bazilian, M., \& Grafham, O. (2016). Energy services for refugees and displaced people. Energy Strategy Reviews, 13, 134-146.

Lei, L., Pinedo, M., Qi, L., Wang, S., \& Yang, J. (2015). Personnel scheduling and supplies provisioning in emergency relief operations. Annals of Operations Research, 235(1), 487-515.

Maleki, A., Khajeh, M. G., \& Ameri, M. (2016). Optimal sizing of a grid independent hybrid renewable energy system incorporating resource uncertainty, and load uncertainty. International Journal of Electrical Power \& Energy Systems, 83, 514-524.

Malekpoor, H., Chalvatzis, K., Mishra, N., Mehlawat, M. K., Zafirakis, D., \& Song, M. (2017). Integrated grey relational analysis and multi objective grey linear programming for sustainable electricity generation planning. Annals of Operations Research. https://doi.org/10.1007/s10479-017-2566-4.

Mandelli, S., Barbieri, J., Mereu, R., \& Colombo, E. (2016). Off-grid systems for rural electrification in developing countries: Definitions, classification and a comprehensive literature review. Renewable and Sustainable Energy Reviews, 58, 1621-1646.

Merei, G., Berger, C., \& Sauer, D. U. (2013). Optimization of an off-grid hybrid PV-wind-diesel system with different battery technologies using genetic algorithm. Solar Energy, 97, 460-473.

Mete, H. O., \& Zabinsky, Z. B. (2010). Stochastic optimization of medical supply location and distribution in disaster management. International Journal of Production Economics, 126(1), 76-84.

Mohamadi, A., \& Yaghoubi, S. (2017). A bi-objective stochastic model for emergency medical services network design with backup services for disasters under disruptions: An earthquake case study. International Journal of Disaster Risk Reduction, 23, 204-217.

Mundada, A. S., Shah, K. K., \& Pearce, J. M. (2016). Levelized cost of electricity for solar photovoltaic, battery and cogen hybrid systems. Renewable and Sustainable Energy Reviews, 57, 692-703.

Omer, J., \& Farges, J. L. (2013). Hybridization of nonlinear and mixed-integer linear programming for aircraft separation with trajectory recovery. IEEE Transactions on Intelligent Transportation Systems, 14(3), 1218-1230.

Opricovic, S. (1998). Multicriteria optimization of civil engineering systems. Faculty of Civil Engineering, Belgrade, 2(1), 5-21.

Özlen, M., \& Azizoğlu, M. (2009). Multi-objective integer programming: A general approach for generating all non-dominated solutions. European Journal of Operational Research, 199(1), 25-35.

Pappas, D., \& Chalvatzis, K. J. (2017). Energy and industrial growth in India: The next emissions superpower? Energy Procedia, 105, 3656-3662.

Pappas, D., Chalvatzis, K. J., Guan, D., \& Li, X. (2017). Industrial relocation and $\mathrm{CO}_{2}$ emission intensity: Focus on the potential cross-country shift from China to India and SE Asia. Energy Procedia, 142, 2898-2904.

Paul, J. A., \& MacDonald, L. (2016). Optimal location, capacity and timing of stockpiles for improved hurricane preparedness. International Journal of Production Economics, 174, 11-28.

Peerapong, P., \& Limmeechokchai, B. (2017). Optimal electricity development by increasing solar resources in diesel-based micro grid of island society in Thailand. Energy Reports, 3, 1-13.

Pepermans, G., Driesen, J., Haeseldonckx, D., Belmans, R., \& D’haeseleer, W. (2005). Distributed generation: Definition, benefits and issues. Energy Policy, 33(6), 787-798.

Pothitou, M., Hanna, R. F., \& Chalvatzis, K. J. (2016). Environmental knowledge, pro-environmental behaviour and energy savings in households: An empirical study. Applied Energy, 184, 1217-1229.

Pothitou, M., Hanna, R. F., \& Chalvatzis, K. J. (2017). ICT entertainment appliances' impact on domestic electricity consumption. Renewable and Sustainable Energy Reviews, 69, 843-853.

Rae, C., \& Bradley, F. (2012). Energy autonomy in sustainable communities-A review of key issues. Renewable and Sustainable Energy Reviews, 16(9), 6497-6506.

Ransikarbum, K., \& Mason, S. J. (2016). Multiple-objective analysis of integrated relief supply and network restoration in humanitarian logistics operations. International Journal of Production Research, 54(1), 49-68. 
Rauner, M. S., Schaffhauser-Linzatti, M. M., \& Niessner, H. (2012). Resource planning for ambulance services in mass casualty incidents: A DES-based policy model. Health Care Management Science, 15(3), 254-269.

Rennemo, S. J., Rø, K. F., Hvattum, L. M., \& Tirado, G. (2014). A three-stage stochastic facility routing model for disaster response planning. Transportation Research Part E: Logistics and Transportation Review, $62,116-135$.

Roh, S., Pettit, S., Harris, I., \& Beresford, A. (2015). The pre-positioning of warehouses at regional and local levels for a humanitarian relief organisation. International Journal of Production Economics, 170, 616-628.

Rueda-Medina, A. C., Franco, J. F., Rider, M. J., Padilha-Feltrin, A., \& Romero, R. (2013). A mixed-integer linear programming approach for optimal type, size and allocation of distributed generation in radial distribution systems. Electric Power Systems Research, 97, 133-143.

Safar, P. (1986). Resuscitation potentials in mass disasters. Prehospital and Disaster Medicine, 2(1-4), 34-47.

Salehin, S., Zhang, H., Larriba, T., Papakokkinos, G., Bowler, E., \& van Kasteren, J. M. N. (2011). Designing of an Emergency Energy Module for relief and refugee camp situations: Case study for a refugee camp in Chad-Sudan border. In Sustainable technologies (WCST), 2011 World Congress on (pp. 9-14). IEEE.

Sen, R., \& Bhattacharyya, S. C. (2014). Off-grid electricity generation with renewable energy technologies in India: An application of HOMER. Renewable Energy, 62, 388-398.

Shahzad, M. K., Zahid, A., Rashid, T., Rehan, M. A., Ali, M., \& Ahmad, M. (2017). Techno-economic feasibility analysis of a solar-biomass off grid system for the electrification of remote rural areas in Pakistan using HOMER software. Renewable Energy, 106, 264-273.

Siddaiah, R., \& Saini, R. P. (2016). A review on planning, configurations, modeling and optimization techniques of hybrid renewable energy systems for off grid applications. Renewable and Sustainable Energy Reviews, 58, 376-396.

Singh, A., Baredar, P., \& Gupta, B. (2015). Computational simulation \& optimization of a solar, fuel cell and biomass hybrid energy system using HOMER pro software. Procedia Engineering, 127, 743-750.

Sinha, S., \& Chandel, S. S. (2015). Review of recent trends in optimization techniques for solar photovoltaic-wind based hybrid energy systems. Renewable and Sustainable Energy Reviews, 50, 755-769.

Smith, K., \& Petley, D. N. (2008). Environmental hazards: Assessing risk and reducing disaster (5th ed.). New York: Routledge.

Spyropoulos, G. C., Chalvatzis, K. J., Paliatsos, A., \& Kaldellis, J. K. (2005). Sulphur dioxide emissions due to electricity generation in the Aegean Islands: Real threat or overestimated danger? In 9th international conference on environmental science and technology.

Strantzali, E., Aravossis, K., \& Livanos, G. A. (2017). Evaluation of future sustainable electricity generation alternatives: The case of a Greek island. Renewable and Sustainable Energy Reviews, 76, 775-787.

Streimikiene, D., Balezentis, T., Krisciukaitienė, I., \& Balezentis, A. (2012). Prioritizing sustainable electricity production technologies: MCDM approach. Renewable and Sustainable Energy Reviews, 16(5), 33023311.

Sung, I., \& Lee, T. (2016). Optimal allocation of emergency medical resources in a mass casualty incident: Patient prioritization by column generation. European Journal of Operational Research, 252(2), 623-634.

Uchida, N., Takahata, K., Shibata, Y., \& Shiratori, N. (2012). A large scale robust disaster information system based on never die network. In Advanced information networking and applications (AINA), 2012 IEEE 26th international conference on (pp. 89-96). IEEE.

UNHCR (United Nations High Commissioner for Refugees). (2017). Figures at a Glance. http://www.unhcr. org/uk/figures-at-a-glance.html. Accessed 3 March 2018.

Van de Kaa, G., Rezaei, J., Kamp, L., \& de Winter, A. (2014). Photovoltaic technology selection: A fuzzy MCDM approach. Renewable and Sustainable Energy Reviews, 32, 662-670.

Vanajakumari, M., Kumar, S., \& Gupta, S. (2016). An integrated logistic model for predictable disasters. Production and Operations Management, 25, 791-811.

Veerapen, N., Ochoa, G., Harman, M., \& Burke, E. K. (2015). An integer linear programming approach to the single and bi-objective next release problem. Information and Software Technology, 65, 1-13.

Wang, Y., De Schutter, B., van den Boom, T. J., \& Ning, B. (2013). Optimal trajectory planning for trains-A pseudospectral method and a mixed integer linear programming approach. Transportation Research Part C: Emerging Technologies, 29, 97-114.

Xiang, Y., \& Zhuang, J. (2016). A medical resource allocation model for serving emergency victims with deteriorating health conditions. Annals of Operations Research, 236(1), 177-196.

Yushimito, W. F., Jaller, M., \& Ukkusuri, S. (2012). A Voronoi-based heuristic algorithm for locating distribution centers in disasters. Networks and Spatial Economics, 12(1), 21-39.

Zafirakis, D., \& Chalvatzis, K. J. (2014). Wind energy and natural gas-based energy storage to promote energy security and lower emissions in island regions. Fuel, 115, 203-219. 
Zafirakis, D., Chalvatzis, K. J., \& Baiocchi, G. (2015). Embodied $\mathrm{CO}_{2}$ emissions and cross-border electricity trade in Europe: Rebalancing burden sharing with energy storage. Applied Energy, 143, 283-300.

Zafirakis, D., Chalvatzis, K. J., Baiocchi, G., \& Daskalakis, G. (2016). The value of arbitrage for energy storage: Evidence from European electricity markets. Applied Energy, 184, 971-986.

Zafirakis, D., Elmasides, C., Sauer, D. U., Leuthold, M., Merei, G., Kaldellis, J. K., et al. (2014). The multiple role of energy storage in the industrial sector: Evidence from a Greek industrial facility. Energy Procedia, $46,178-185$.

Zobel, C. (2010). Improving Supply Chain Management for Disaster Relief. VirginiaTech Pamplin College of Business Magazine. Retrieved August 10, 2011, from http://www.magazine.pamplin.vt.edu/fall10/ supplychain.html. 